\title{
Artículos
}

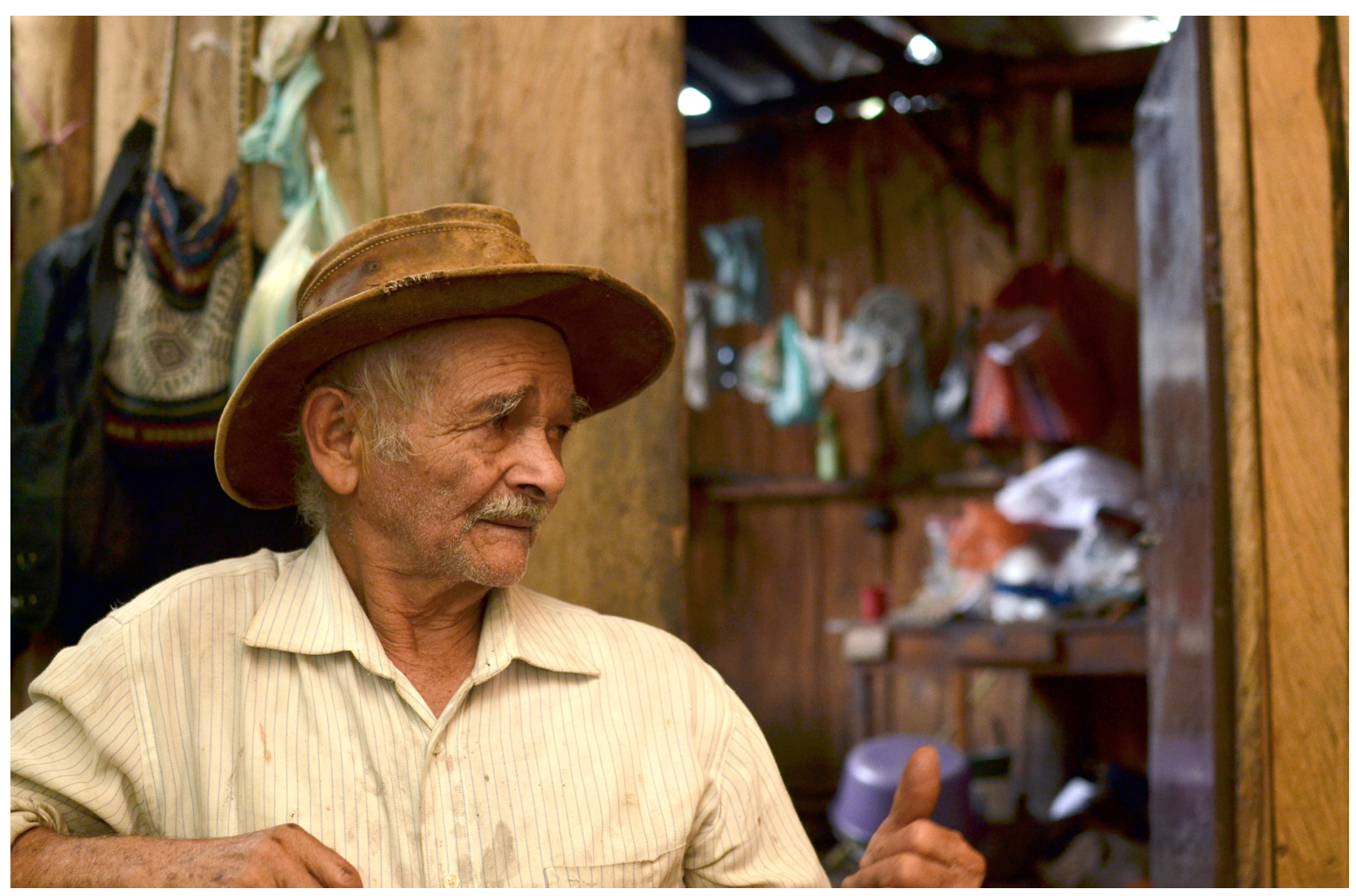

Campesino de Miraflores. Boyacá 


\section{“Cultura ciudadana” en Bogotá: biopolítica, hegemonización y pánico cultural en la época del culturalismo $^{2}$}

"Citizen culture" in Bogotá: biopolitics, hegemonization and cultural panic in the epoch of the culturalism Cultura cidadã em Bogotá: biopolítica, hegemonização e pânico cultural na época do culturalismo

\section{Resumen}

Este artículo examina cómo se ha naturalizado una idealización y romantización de la noción de "cultura ciudadana". Con ello se pretende mostrar que, contrario a esas percepciones idílicas, lo que está en juego con esta noción-estrategia es una modalidad de biopolítica que produce un "pánico cultural" para producir un particular sujeto - un ciudadano adecuado- desde retóricas salvacionistas, las cuales que despliegan un autoritarismo moral eurocentrado y clasista. El logro más destacado de la "cultura ciudadana" no es lo que los expertos y burócratas celebran desde estadísticas de "seguridad" y "bienestar", sino su hegemonización, que oblitera el entender las problemáticas de una ciudad desde perspectivas diferentes a su reduccionismo culturalista.

Palabras clave: Cultura ciudadana, pánico cultural, biopolítica, Antanas Mockus.

Recibido: 30 de abril de 2016, evaluado: 20 de mayo de 2016, aprobado: 20 de mayo de 2016

1 Doctor en Antropología (con énfasis en Estudios Culturales), Universidad de Carolina del Norte-Chapel Hill. Profesor asociado, Departamento de Estudios Culturales. Pontificia Universidad Javeriana. Correo electrónico: eduardoa.restrepo@gmail.com

2 Este es un texto escrito en el marco del Seminario de investigación en estudios culturales de la Maestría en Estudios Culturales de la Universidad Javeriana. Agradezco a Juan José Rondón y Nathaly Gómez por sus aportes y comentarios a las versiones previas de este artículo. 


\begin{abstract}
This article examines how the notion of "citizen culture" has been naturalized as an idealized and romanticized idea. With this it's intended to show that, contrary to those idyllic perceptions, what is truly at stake with this notion-strategy is a modality of biopolitics that produces a "cultural panic" in order to produce a particular subject - an appropriate citizen - using salvationism rhetorics, which put in practice a moral Eurocentred and classist authoritarianism. The most significant achievement of the "citizen culture" is not what experts and bureaucrats celebrate from "security" and "well-being", but its hegemonizing process that forgets the understanding of the city problematics from perspectives different than its cultural reductionism.
\end{abstract}

Keywords: citizen culture, cultural panic, biopolitics, Antanas Mockus.

\title{
Resumo
}

Este artigo examina como se tem naturalizado uma idealização e romantização da noção de "cultura cidadâ" mostrando que, contrário a essas percepções idílicas, o que está em jogo com esta noção-estratégia é uma modalidade de biopolítica que produz um "pânico cultural" para produzir um particular sujeito — um cidadão adequado - desde retóricas salvacionistas que despliegan um autoritarismo moral eurocentrado e clasista. O lucro mais destacado da "cultura cidadã" não é o que os experientes e burócratas celebram desde estatísticas de "segurança" e "bem-estar", sina sua hegemonización que oblitera entender as problemáticas de uma cidade desde perspectivas diferentes a sua reducionismo culturalista.

Palavras-chave: Cultura cidadã, pânico cultural, biopolitica, Antanas Mockus. 


\section{Introducción}

En Colombia el término "cultura ciudadana" ha estado asociado a Antanas Mockus ${ }^{3}$, quien fue alcalde de Bogotá en dos ocasiones (1995-1997 / 2001-2003). Su plan de gobierno tuvo como centro una serie de acciones en torno a la "cultura ciudadana”, y desde entonces, junto con su Fundación Corpovisionarios, se ha dedicado a promover la "cultura ciudadana" por diferentes ciudades del país y el extranjero. Ha sido contratado innumerables veces para asesorar distintas alcaldías y otras entidades municipales, lo cual a menudo ha implicado la realización de encuestas de cultura ciudadana en diferentes lugares.

"Cultura ciudadana" suele asociarse hoy a algo positivo, a una deseada forma del comportamiento colectivo para superar los problemas de la ciudad. Se la invoca en diferentes escenarios como una solución ideal que apela a imaginativas campañas pedagógicas como la recordada utilización de mimos en las calles de Bogotá. Articulada a nociones como convivencia, pedagogía, respeto y bienestar común, el término de "cultura ciudadana" es ampliamente valorado por ciertos sectores sociales y de la clase política.

No cabe duda que, cualesquiera que sean sus contenidos, "cultura ciudadana" se ha asociado a ideas que han seducido la imaginación social y política más allá de Mockus. En comparación con esta inusual interpelación, los estudios y debates académicos sobre "cultura ciudadana" son más parcos y con marcado predominio de las interpretaciones celebratorias que usualmente se circunscriben a reiterar las líneas de argumentación sugeridas por Mockus. Para algunos académicos, incluso, Mockus es una destacada figura en América Latina de la agencia cultural en la acción colectiva (cf. Sommer, 2006; Tognato, n.d.).
En contraste con estas apreciaciones celebratorias e idílicas de la "cultura ciudadana", en este artículo me interesa explorar cómo en su nombre se despliegan unas tecnologías de gobierno que, a partir de la invención de un "pánico cultural", agencian un autoritarismo moral abiertamente eurocéntrico y clasista. Nada hay de ingenuo o neutral con las apelaciones a la "cultura ciudadana". Su éxito radica en gran parte en que ha sido "buena para gobernar" en su despliegue de una serie de racionalidades y tecnologías de gobierno de los otros y de sí, lo que ha desagregado ciudadanos moralmente buenos y malos en nombre del "bienestar de todos".

Recurriendo a los aportes teóricos de Michel Foucault sobre el poder y de Antonio Gramsci sobre hegemonía, en este artículo argumento que la "cultura ciudadana" constituye una particular modalidad de biopolítica que ha logrado hegemonizar el imaginario social y político al naturalizarse como deseable. Es esta hegemonización el logro más sorprendente de la "cultura ciudadana", no los supuestos beneficios ni las estadísticas autocelebratorias que los gobernantes a menudo presentan para legitimar sus gestiones.

3 Mockus, con formación en matemáticas y filosofía, ha sido profesor y rector de la Universidad Nacional de Colombia. Fue elegido posteriormente como alcalde con su inusual candidatura, cargo al que renunció para aspirar a la presidencia sin lograrlo. Vuelve a ser alcalde de Bogotá por segunda ocasión luego de pedir disculpas por abandonar el cargo. Su nombre figura en varias oportunidades como posible candidato a la presidencia, pero es en las elecciones de 2010 donde adquiere mayor fuerza su candidatura y pasa a segunda vuelta. 
manera amorosa y consciente las reglas y reconocen la importancia del respeto por lo público. Se trata de aprender a reconocer los invaluables beneficios para la persona y para la sociedad que se derivan de la capacidad de trabajar por el bien común (Alcaldía Mayor de Bogotá, 2003, p. 6).

Desde el conjunto de supuestos que constituyen el discurso de la "cultura ciudadana", se derivan una serie de correlaciones que hacen que para Mockus aparezcan como constataciones triviales, "hipótesis sencilla", autoevidente o tautológica. No obstante, cuando los principios de inteligibilidad de lo social y de lo político son otros, el mundo no es necesariamente tan simple ni las intervenciones desde la "cultura ciudadana" son tan "altruistas" como suelen presentarse. Pero antes de "aguar la fiesta", examinemos desde las narrativas de sus proponentes cuáles fueron las prácticas y acciones desplegadas en nombre de la "cultura ciudadana".

El punto nodal de estas prácticas fue concebido explícitamente como la modificación de los comportamientos ciudadanos. Fueron los comportamientos el objeto de intervención, devinieron problemáticas para el pensamiento y el gobierno de una población. En una nota de prensa, titulada Siete caras de la perinola, se escribía que Paul Bromberg: "tendrá la responsabilidad, al lado del alcalde Mockus, de liderar el programa de Cultura Ciudadana, un proyecto con objetivos claros que incluye el modificar comportamientos de los ciudadanos, protagonistas directos" (El Espectador, 9 de enero de 1995, p. 1-E). Desde el comienzo, entonces, es bien claro que lo que se propone con la noción de la "cultura ciudadana" es la modificación de comportamientos que parecían inadecuados a los ojos de la administración; una modificación hacia un conjunto de comportamientos adecuados, la búsqueda de la transformación de unos "inadecuados ciudadanos" - o unos "no ciudadanos" - en unos "buenos ciudadanos", unos "ciudadanos modelos".

Hecho tal diagnóstico y establecida esa ruta, el siguiente paso consistía obviamente en que había que enseñárselo a los bogotanos. Mockus y su equipo se colocan en el lugar del profesor que enseña, mediante una serie de estrategias pedagógicas, cómo debe ser el comportamiento adecuado de los ciudadanos para transformar las prácticas que consideran no solo inapropiadas, sino la raíz más profunda de los males de la ciudad en su conjunto. Refiriéndose al Plan de desarrollo de Bogotá, en una entrevista en la radio capitalina transcrita en algunos apartes en la prensa, Mockus enfatizaba lo de "formar ciudadanos" como el aspecto central, y esta formación es entendida como "cambio de mentalidad":

$Y$ es que el plan para seguir está basado en un objetivo claro. La prioridad de la administración es formar a los ciudadanos, porque a pesar de que no se olvidaron los aspectos relacionados con las vías, seguridad, obras públicas, transporte, impuestos, entre otros, desde un comienzo se planteó la necesidad de buscar un cambio de mentalidad [subrayado ajeno al texto] (El Espectador, 6 de marzo de 1995, p. 2-E).

La "formación de ciudadanos" supone que no hay "ciudadanos" o, si los hay, estos no son adecuados. Un cambio de mentalidad: de una mentalidad rechazable - que es considerada la raíz cardinal de los problemas de la ciudad - a una armonizada con la ley, con las reglas, con la "convivencia" y el "respeto". Tecnologías de intervención que pretenderían producir ciudadanos dóciles a la ley, a las reglas, que tramitan racionalmente y mediante el dialogo sus conflictos, en fin, producir sujetos y mentalidades adecuadas para el gobierno de la ciudad - en gran parte a través del gobierno de sí-.

No solo los comportamientos ilegales, sino los comportamientos inadecuados fueron objeto de la estrategia de cultura ciudadana; un reforzamiento moral y cultural de la ley con respecto al comportamiento de los otros y al comportamiento propio. La "cultura ciudadana" es explícitamente enunciada como estrategia de gobierno, una que evidenciaba y rechazaba comportamientos inadecuados en los otros y, a su vez, en sí mismo, una nueva imbricación para gobernar/se:

Mediante mensajes intensos sobre los objetivos de la ley ylas medidas destinadas a lograr su cumplimiento, el programa [de cultura ciudadana] logró una mayor armonía entre la moral, la ley y la cultura. Ello 
demuestra que la modificación consciente de los hábitos y creencias de la colectividad puede llegar a ser un componente crucial de la gestión pública y de la agenda común del Gobierno y de la sociedad civil [subrayado ajeno al texto] (Mockus, 2001, p. 1).

La idea de ciudadanos adecuados, aquellos que se apropian de la "cultura ciudadana" enseñada a los bogotanos por Mockus y su equipo, suponía trascender las barreras entre la sociedad civil y la autoridad del estado y sus gobernantes. El propósito era la incorporación de la permanente y detallada vigilancia de los comportamientos de los otros y los propios en aras de cumplir y respetar las "reglas":

Hacer cultural y moralmente válidas las prescripciones legales y combatir la justificación moral o la aceptación social o cultural de comportamientos ilegales fueron, en síntesis, el eje de la acción de la Alcaldía de Bogotá en el período de 1995-1997. Mientras se acuda a compensaciones culturales y morales y a medios pacíficos, no hay una barrera esencial que separe a la ciudadanía de la autoridad. Las acciones necesarias para hacer cumplir y respetar las reglas podrían recaer sobre cualquiera (Mockus, 2001, p. 23).

Si esto de "formar ciudadanos" se constituye como una prioridad de la administración de Mockus no es de extrañar que se haya traducido en la destinación al IDCT de un significativo presupuesto para financiar una serie de intervenciones que, en una apelación a la lúdica y la creatividad, inicialmente se denominaron "juegos ciudadanos":

Para desarrollar este programa [Cultura ciudadana] el IDCT cuenta con $\$ 23$ mil millones, el más alto presupuesto designado desde su creación. El
Instituto se encargará de liderar y promover la participación de la comunidad en los juegos ciudadanos y explicarle a la gente los usos del medio urbano [...] El primer programa: identificar comportamientos simples y específicos de la gente, con los que se pueda trabajar y que se desarrollará sin contaminar visualmente el espacio público. (El Espectador, 9 de enero de 1995, p. 1-E)

Esto no significa que esta estrategia se despliegue desde lo pedagógico sin recurrir a la autoridad, a la coerción. De ahí que Paul Bromberg conciba la estrategia de la cultura ciudadana como una "ingeniería de la autoridad":

Cuando el propósito de cultura ciudadana se convirtió en acciones de gobierno en Bogotá, rápidamente se descubrió la necesidad de actuar en todas las modalidades - autoridad, invocaciones éticas, presión social - en cada situación. Sin autoridad no se logrará el cumplimiento de las normas de convivencia urbana, porque siempre habrá una porción de ciudadanos que no se mostrarán dispuestos. Hay comportamientos desviados en una sociedad liberal, y algunos de ellos serán palmariamente delitos, que requieren acción de autoridad. Es decir, "por las buenas" no aplica para todos. La ingeniería de autoridad requiere no considerar que la ciudadanía sea homogénea en su disposición o en su no-disposición a cumplir las normas (2010, p. 53).

Intentando también por las buenas, pero empleando la "autoridad con ingenio", no la autoridad a secas, es como Bromberg diferencia la cultura ciudadana para que no caiga en "ingeniería cultural de baja calidad" como parecen haberla malentendido algunos alcaldes municipales en Colombia ${ }^{4}$. De ahí que concluya tajantemente: "La lección que enseñan las políticas de cultura ciudadana exitosas [...] es que la mejor manera

4 "[...] cultura ciudadana es una acción de gobierno dirigida a transformar comportamientos colectivos [el énfasis es en los comportamientos], aplicando lo que es propio del sello de cultura ciudadana: intentando también 'por las buenas'. Esta es la versión que adoptan espontáneamente los alcaldes municipales que en Colombia quieren 'hacer cultura ciudadana': actuar desde las herramientas estatales de un régimen liberal para conseguir el cumplimiento de las normas por las buenas, ya que por las malas no quieren, no pueden 0 no lo consideran políticamente correcto. Palabras más, palabras menos: "No vamos a actuar mediante la policía para hacer cumplir las normas, solamente vamos a producir un nuevo ciudadano". Preocupa tamaño despropósito: ya que no podemos lo fácil, hacer lo difícil, ingeniería cultural de baja calidad. Se requiere, primero que todo, voluntad política para hacer cumplir las normas; y luego ejemplo por parte de las autoridades públicas, y policía bien administrada, 'ingeniería de autoridad"' (Bromberg, 2003, pp. 52-53). 
de hacer que las ciudades sean gobernables es gobernándolas. Por supuesto, gobernándolas bien" (2010, p. 53).

Es bajo estos postulados que se diseñó e implementó la estrategia de la "cultura ciudadana": "ingeniería de la autoridad con ingenio". En un balance de las acciones adelantadas en este marco, Mockus (2001) resaltaba las siguientes: tarjetas ciudadanas; mimos y cebras; creación del Boletín de Violencia y Delincuencia, "Ley zanahoria"; prohibición de la pólvora; Plan de desarme y desarme voluntario; jornadas de "vacunación contra la violencia”; policías formadores de ciudadanos; jornadas "Re" — conciliación- y solución pacífica de conflictos; "Carta de civilidad" y "Semilleros de convivencia"; interrupción de las relaciones clientelistas entre el gobierno y el Consejo; paros y amenazas de paro; concertar para planear con participación; eventos culturales en el espacio público; y ahorro de agua ${ }^{5}$ (pp. 9-20).

La mayoría de estas acciones indican los "cambios deseados", una "descripción” y "algunos resultados". En algunas se incluye también un breve aparte de "antecedentes". Así, para las "tarjetas ciudadanas" se escribe como cambios deseados: "que unos ciudadanos regularan el comportamiento de otros de manera pacífica” (Mockus, 2001, p. 9). Luego de una breve descripción de cómo son las tarjetas, junto a algunos resultados, se escribe:

[...] muchos conductores utilizaron la tarjeta y algunos la conservan adherida permanentemente a una de las ventanas de su vehículo. La cara roja fue utilizada con mayor frecuencia - para censurar comportamientos indebidos por parte de peatones o de conductores de vehículos-. También usan la cara blanca con el pulgar hacia arriba quienes desean reconocer o agradecer comportamientos ciudadanos destacables o positivos. En algunas situaciones de conflicto, los sindicatos y las comunidades expresan desaprobación usando grandes tarjetas con el dedo hacia abajo o haciendo el mismo gesto con la mano. (Mockus, 2001, pp. 9-10)

Pareciera, entonces, que las tarjetas cumplieron su cometido. El tono de triunfo y acierto no se limita a esta actividad, sino que es generalizable a las otras. En algunas de éstas, tal tono se enuncia recurriendo a las estadísticas ${ }^{6}$. Por ejemplo, en la actividad de "mimos y cebras", luego de indicar que el cambio deseado era "una mejor convivencia entre peatones y conductores de vehículos y mayor conciencia de la conveniencia de tener y observar reglas de convivencia" (Mockus, 2001, p. 10), y de una relativamente detallada descripción de la actividad, se anotan como resultados:

[...] la campaña educativa se realizó en 482 intersecciones viales y tuvo la participación de 425 personas - entre mimos, agentes de policía, etc.,-—. Se demarcaron 364 intersecciones en la ciudad. El buen resultado de los paraderos se vio especialmente en la Calle 80 , una de las vías de mayor densidad y congestión de la ciudad. El número de pasajeros que respetaban los paraderos subió de $26,2 \%$ en 1995 a $38 \%$ en 1996 ; y entre febrero y mayo de 1997 43\% de las busetas los respetaban. El programa para inculcar el respeto a las cebras fue uno de los que dio mejores resultados; los mismos ciudadanos empezaron a ejercer un gran control social sobre los infractores. En 1996, el $76,46 \%$ de los conductores y el $72,25 \%$ de los peatones respetaban la cebra. Lo que distinguió a estas campañas fue su concepción lúdica y no represiva en la promoción del cumplimiento de las normas de tránsito (Mockus, 2001, pp. 10-11).

Otra de las acciones más visibilizadas de la administración Mockus fue la llamada "Ley zanahoria”. Como antecedentes se enuncia una correlaccion

5 Las comillas y los nombres son los que utiliza Mockus en su documento.

6 La producción de estadísticas, la cuantificación como epítome del discurso experto, fue central en la estrategia de la "cultura ciudadana", no solo en cuanto al establecimiento de diagnósticos sino en poner en evidencia sus resultados. Los efectos de verdad de la dimensión estadística del discurso y prácticas de la cultura ciudadana ameritaron el diseño e implantación de la Primera encuesta de cultura ciudadana en el 2001 en Bogotá, desde el Observatorio de cultura adscrito a la Alcaldía. Desde entonces, se han realizado otras cuatro encuestas en Bogotá, así como en gran parte de las otras ciudades del país y algunas en el extranjero — México, Brasil, Venezuela, Bolivia, Ecuador, Paraguay, Uruguay y Suecia—. Para los años de las encuestas, adelantadas de la Fundación Corpovisionarios (Corpovisionarios, 2016). 
entre muertes violentas y accidentes de tránsito con el consumo de alcohol. Para esto, nuevamente, se apela al efecto de verdad de las estadisticas:

En 1995, el 49\% de los muertos en accidentes de tránsito, el $33 \%$ de los homicidios con armas de fuego, el $49 \%$ de los homicidios con armas cortopunzantes, el $35 \%$ de los suicidios y el $10 \%$ de las muertes accidentales mostraron una asociación con concentraciones de alcohol elevadas en la sangre de las víctimas (Mockus, 2001, p. 11).

De ahí que con la imposición del cierre de estancos y establecimientos nocturnos a la una de la mañana, se pretendía como cambios deseados la: "[...] reducción de las muertes violentas ocasionadas o facilitadas por el abuso del alcohol" (Mockus, 2001, p. 11). Nuevamente, la descripción del éxito es incontestablemente enunciada desde la fuerza de las estadísticas:

[...] en 1995, los homicidios con concentraciones detectables de alcohol en la sangre se redujeron en 9,5\%. Las muertes en accidentes de tránsito en que alguna de las personas involucradas estaba embriagada disminuyeron 24,2\%. En la Navidad de 1996 los homicidios bajaron en $26,7 \%$. Y en 1997 , en comparación con 1996, se redujeron en $15 \%$ los homicidios comunes y en $13 \%$ las muertes en accidentes de tránsito (Mockus, 2001, pp. 11-12).

Se asume no solo que las estadísticas son confiables, sino que hay una correlación causal entre la prohibición y las diferencias en las estadísticas.

Se sigue la descripción de una serie de acciones: las de la prohibición de la polvora, el plan de desarme, el desarme voluntario, las jornadas de vacunación contra la violencia, y policias formadores de ciudadanos, que referían como cambios deseados revertir cifras en el número de niños quemados o de muertes violentas, así como la de establecer mecanismos de convivencia intrafamiliar y en escenarios públicos entre los bogotanos o entre éstos y la policía. También se menciona el programa de "Semilleros para la convivencia" y la "Carta de civilidad". Nuevamente, en la parte de los resultados el tono es el de significativos logros, muchos de ellos glosados estadísticamente. Hasta aquí ninguna crítica a las diferentes acciones en las narrativas (auto)celebratorias del exalcalde. Aciertos por doquier, ninguna sombra de duda o problematización sobre el despliegue de acciones enmarcadas en los supuestos de la cultura ciudadana.

El relato sobre las acciones continúa con las siguientes tres acciones: "interrupción de las relaciones clientelistas entre el gobierno y el Consejo", "paros y amenazas de paro", y "concertar para planear con participación”. En su conjunto, estas acciones se presentan como la ruptura de las redes clientelares, la utilización del "chantaje" por parte de ciertos sectores y la apelación a la planeación con participación ciudadana. La descripción sigue el modelo de las otras actividades, esto es, mostrar cómo las acciones de la administración modificaban nefastas prácticas que respondían a intereses particulares - como el clientelismo o la amenaza de paro- o apuntalaban unas que permitían el bien común - como la bienvenida participación ciudadana en la elaboración de planes de desarrollo local- . Las tres acciones resaltan lo valioso de la argumentación racional y el saldo pedagógico para la ciudadanía sobre nuevas reglas, lo anterior desde el tono celebratorio de lo maravillosas y acertadas de estas acciones.

El análisis de las acciones cierra con "eventos culturales en el espacio público" y con el "ahorro de agua". El primero buscaba "[...] promover 'el goce zanahorio' y el regreso al espacio público del parque" (Mockus, 2001, p. 18). Los eventos culturales listados son Rock al parque, Rap a la torta, Jazz al parque, Rap and roll, Septimazos, Música en los templos y Cinema al espacio público. Los resultados, nuevamente, son presentados con el efecto demostrativo de las estadísticas ${ }^{7}$. Por su parte, el ahorro voluntario de agua se gestó ante el probable razonamiento de este vital líquido debido a fuertes daños en la infraestructura que surte a la ciudad. Nuevamente, estadísticas que ratifican lo acertado de la acción: 
[...] la campaña 'Ahorro de agua' permitió superar la emergencia, que duró varios meses, sin racionamiento. Durante cerca de 20 semanas se logró un ahorro de agua de $8 \%$ a $12 \%$. Desde la emergencia, el ahorro se ha mantenido en el 5\% (Mockus, 2001, p. 20).

Con la llegada nuevamente a la alcaldía de Mockus se habla de un cambio en su programa base de "cultura ciudadana" en el que "no habrá mimos, ni tarjetas, sino mensajes muy claros de cambio cultural voluntario. $Y$ en competitividad es clave recuperar el clima de seguridad y hacer la ciudad atractiva para invertir" (Semana, diciembre 4 de 2000). En otro artículo publicado en la misma revista, se mostraba cómo en esta segunda administración la "cultura ciudadana" buscaba "[...] demostrar que Bogotá tiene un perfil de ciudad 'civilizada' candidata a la inversión externa y que cualquiera puede vivir ahí" (Semana, junio 11 de 2001).

Uno de los programas más visibles para demostrar el perfil de "ciudad civilizada" se denominó Vida sagrada. Enmarcada en bajar indicadores, "el reto más importante del programa 'Vida sagrada' es continuar el proceso de valorar la vida como el más sagrado de los bienes [...]"; para lo cual había que insistir "[...] en la autorregulación, la mutua regulación, la confianza y la solidaridad entre los ciudadanos para que continúe la disminución del número de muertes violentas en la ciudad" (Alcaldía Mayor de Bogotá, 2003, p. 39). Muy en sintonía con las ansias globales internacionales - Bush-y locales - Uribe- frente al terrorismo, este programa se conectaba con los retos de disminuir la fuerza de la "delincuencia organizada" y contrarrestar la "acción del terrorismo":

Otro desafío es aumentar la percepción de seguridad de la ciudadanía y lograr una mayor colaboración con las autoridades, especialmente en los momentos en los que vive el país, en los cuales el conflicto armado incrementa la delincuencia organizada: por tanto, otro reto es convertir la resistencia civil en acción colectiva para contrarrestar la acción del terrorismo (Alcaldía Mayor de Bogotá, 2003, p. 40).

No todas las acciones estaban orientadas a la seguridad. La transparencia en el manejo de los recursos públicos, con el propósito de que los contribuyentes pagaran sus impuestos de "buena gana", también encajaba en la agenda de la "cultura ciudadana” de la segunda alcaldía de Mockus: "El programa 'Aportar de buena gana' se ha propuesto como reto lograr que más personas conozcan el destino de los diferentes recaudos por impuestos y bienes públicos que hace el Distrito y confíen el uso que se hacen de ellos" (Alcaldía Mayor de Bogotá, 2003, p. 40).

En el más estricto sentido de la "cultura ciudadana”, en esta alcaldía no faltó un programa llamado "Apreciar las normas y admirar lo bueno". En este se buscaba que "[...] más ciudadanos acaten con plena conciencia las normas básicas de convivencia, por ejemplo en materia de derechos humanos, medio ambiente, espacio público, urbanismo y tránsito, y del nuevo Código de Policía de Bogotá" (Alcaldía Mayor de Bogotá, 2003, p. 40). El complemento era otro programa para que "[...] más ciudadanos incrementen su capacidad para celebrar y cumplir los acuerdos, y que puedan percibir los derechos como tales y no como favores, y que aumenten el nivel de confianza en los procedimientos democráticos" (Alcaldía Mayor de Bogotá, 2003, p. 41). Finalmente, en el listado de programas de la segunda alcaldía aparece el titulado "Comunicar vida y jugar limpio", cuyo propósito radicó en “[...] aumentar la promoción de la demanda y democratización de la oferta cultural, recreativa y deportiva

7 Los resultados anotados son: "en 1995, más de 100 bandas se inscribieron en "Rock al parque"; la asistencia en los dos días de concierto fue de 50.000 jóvenes. En 1996, 120.000 jóvenes escucharon 250 bandas; en 1997, 210.000 personas escucharon 82 bandas nacionales y 9 internacionales y "Rock al parque" montó espectáculos que en conjunto fueron reconocidos por algunos de los participantes como el festival de música rock más importante de América Latina. A la versión inicial de 1995 de "Jazz al parque" fueron 15.000 personas y en 1997 la asistencia se duplicó. A "Rap and Roll" asistieron cerca de 3.000 personas en cada noche de novena navideña, exceptuando la del 24. Se realizaron 10 "septimazos" en los dos años de ejecución del proyecto. "Música en los templos" consistió en 91 conciertos en el segundo semestre de 1996, con buena participación; en 1997, abarcó 250 conciertos en 147 parroquias — 80\% en barrios populares — y asistieron más de 70.000 personas. Se inició una labor pedagógica permanente en el área coral en 21 parroquias" (Mockus, 2001, p. 19). 
del Distrito, mediante la definición de políticas en esos aspectos y el fortalecimiento de la convivencia ciudadana en eventos de esos órdenes en el Sistema Distrital de Parques y Escenarios" (Alcaldía Mayor de Bogotá, 2003, p. 43).

Todos estos programas se enmarcaban en una concepción de la "cultura ciudadana" que prestaba atención a incrementar la productividad y el consumo:

La cultura ciudadana puede ayudar, al menos de tres maneras, a lograr un mayor producto social por unidad de recursos empleados. Por una parte, puede aumentar la productividad de la infraestructura y los servicios colectivos [...] Igualmente, la cultura ciudadana puede ser fuente de aprendizajes aplicables al terreno de la producción de bienes y servicios [...] Por último, la cultura ciudadana sienta bases cruciales para mejorar la cultura del consumidor, puesto que otro de los valores fundamentales que se recupera es la autoestima, junto al sentido de pertenencia que mueve a los bogotanos hacia el deseo de acceder a una mejor calidad de vida (Alcaldía Mayor de Bogotá, 2003, pp. 32-33).

En suma, las acciones desplegadas en la primera y segunda alcaldías de Mockus en nombre de la "cultura ciudadana" se realizan en nombre del "bienestar" de los bogotanos, concretamente en aras de la seguridad, la convivencia y la productividad que buscaban transformaciones en el plano de la cultura.

\section{Naturalización de la "cultura ciudadana"}

Cuando se examina históricamentela emergencia e implementación del concepto-estrategia de la "cultura ciudadana", una de las mayores sorpresas es darse cuenta de que no siempre hubo ese grado de aparente consentimiento sobre su natural relevancia e inmanentes bondades. Uno de los resultados más interesantes para el análisis radica, entonces, en evidenciar el manto de naturalización que hoy parece cubrir a la "cultura ciudadana" como algo deseable $\mathrm{e}$ indispensable. Este tipo de naturalizaciones han sido conceptualizadas desde los estudios culturales como un proceso de hegemonización (Hall, 2010). Es más, como se espera mostrar más adelante, este proceso de hegemonización que ha articulado la "cultura ciudadana" en su más sutil naturalidad ha sido posible por la producción de lo que podríamos denominar un "pánico cultural".

$\mathrm{Al}$ inicio de su primera administración, la "cultura ciudadana” era un concepto todavía brumoso que se mezclaba con conceptos como los de educación y civismo. No era extraño encontrar notas en la prensa que pretendían descifrar lo que esto podría significar:

Este filósofo-rey sabanero llegó como la encarnación de la antipolitiquería colombiana y está dispuesto a ponerlo todo patas arriba en aras de la educación ciudadana. Esa es toda una transformación. Falta saber si la revolución cultural que promete Mockus la ejercerá definitivamente a través de parábolas, como los apóstoles, o mediante la descalificación de sectores sociales, como Mao Tse Tung, pues aún se le perciben síntomas de las dos tendencias (Pombo, 1994).

Un componente fundamental de la naturalización de la "cultura ciudadana" son las narraciones en retrospectiva de su surgimiento y despliegue. En las narrativas más planas y celebratorias, se hace referencia a una situación de "desorden generalizado", de crisis y de caos, ante lo cual Mockus introdujo el necesario "orden" desde las intervenciones de la "cultura ciudadana":

Bogotá había recuperado la gobernabilidad con los logros estructurales conseguidos por el alcalde saliente, Jaime Castro, pero este tipo de acciones de gobierno son reconocidos por los estudiosos, pero no por los ciudadanos-electores. Además, la ciudad vivía un período de prosperidad económica: crecimiento económico inusitado y una de las tasas de desempleo más bajas que se recuerden, posiblemente fruto de los primeros años de la apertura, a medias, del gobierno nacional de César Gaviria, y de condiciones internacionales favorables. Sin embargo, la prestación de todos los servicios a cargo del distrito continuaba siendo desastrosa: crisis en todos los servicios públicos domiciliarios, espacio público deteriorado y convertido en tierra de nadie, inseguridad 
ciudadana, pésimo servicio educativo público, y más [...] En este contexto de deterioro urbano Mockus vino con la cultura ciudadana, y propuso orden, orden urbano. Ciertamente, es posible que el deseo de renovación en la democracia colombiana hubiera permitido a Mockus alzarse con la misma victoria contundente que logró, pero la propuesta de cultura ciudadana, coherente con una nueva política, empató muy bien con un sentimiento que vivía la ciudad de rechazo al desorden generalizado" (Bromberg, 2010, p. 35).

Este tropo apela a una retórica salvacionista que supone el revertir la "falta de organización", el "desorden", que se ensañaba con la ciudad, que en algunas narrativas aparece arraigado como definitorio de lo latinoamericano en contraste con la "cultura" de muchos países europeos. Narrativas que perfilan a las sociedades europeas como Suiza y Alemania como paradigmas de orden social, como referentes y horizontes de articulación de la regulación cultural con la ley y la moral, expresada en la desaprobación a la ilegalidad, como un apego al cumplimiento de las obligaciones legales. En claro contraste con el "desorden latinoamericano" en general o el todavía más caótico desorden bogotano en particular, esas sociedades europeas modernas y con relativa armonía entre los tres sistemas regulatorios, donde los individuos y colectivos se pliegan por la autorregulación de la norma, devienen en paradigmas de civilidad — por no decir que de civilización-:

Todos hemos oído hablar de la organización — vista como una 'cultura' - de muchos países europeos, entre ellos Suiza y Alemania, a manera de ejemplo, contrapuesta al desorden latinoamericano $y$, en nuestro caso, al de Bogotá, donde era del conocimiento común que había aprobación cultural y/o moral para las acciones ilegales y no existía aprobación moral o cultural para las obligaciones legales" (Alcaldía Mayor de Bogotá, 2003, p. 18).

No son pocos los pasajes en donde se pueden identificar los contrastes celebracionistas entre el antes y el después de la intervención salvadora de la estrategia de cultura ciudadana, y el a veces lugar mesiánico otorgado a la figura de Mockus:
Había llegado el momento de cambiar ese estado de cosas. El alcalde Antanas Mockus propuso la educación ciudadana como camino para recuperar la armonía entre ley, moral y cultura. La vía formulada se iniciaba con una primera etapa - para desarrollar entre 1995 y 1997- en la cual 'la noción de cultura ciudadana buscaba impulsar ante todo la autorregulación personal' (Alcaldía Mayor de Bogotá, 2003, p. 22).

Ahora bien, las narrativas de la ciudad de Bogotá como presa del caos, del desorden, no es una invención de Mockus. No obstante, su singularidad consiste en haber sido capaz de articular en términos de la "cultura ciudadana" esta urgencia de "orden", de "seguridad", de "funcionalidad". Esta articulación fue posible a partir de un diagnóstico que se fundamenta conceptualmente en uno de los tres sistemas regulatorios antes comentado que confluye en la idea de "pánico cultural".

Las ansiedades derivadas de las experiencias vividas del creciente caos en la ciudad son interpretadas por Mockus como la expresión de un preocupante "divorcio" entre los tres sistemas regulatorios, de los cuales es el de la cultura el que sitúa como punto de quiebre y el lugar de intervención. Un pánico de "falta" de cultura, del desbordamiento de comportamientos "inadecuados", de preocupantes permisibilidades culturales ante el incumplimiento de la ley y las normas es lo que Mockus instala en el imaginario social y político bajo la egida de la "cultura ciudadana".

La invención de este "pánico cultural" es producido en gran parte por sus propias interpretaciones, las cuales operan en sus efectos performativos como un paquete de diagnóstico-solución encarnado en su noción de "cultura ciudadana". No es que una situación problemática no fuera experimentada y representada por amplios sectores y varios medios. No obstante, la creciente desazón con el transporte, con la violencia, con el sentimiento de crisis, con el desorden, no tenía que ser articulada en clave de una falla de cultura, no había una necesaria correspondencia con la instalación de un pánico cultural, con la urgencia de transformar comportamientos de los bogotanos desde una retórica culturalista. 
Que esto haya sucedido así y no de otra manera no se explica simplemente por la impronta personal de Mockus. La confluencia en la década de 1990 del giro al multiculturalismo en la Constitución Política de 1991, la creación del Ministerio de Cultura y la angustia de ciertos sectores de las elites por el posicionamiento de un narcotráfico que amenazaba los privilegios de la "gente de bien", que puso a circular nociones como "cultura de la muerte" o "cultura de la violencia" son, entre otros, algunos de los factores que perfilan que Mockus apelara con particular ahínco a la noción de "cultura" y no a las de pedagogía o civismo, que también circulaban para la época, en su discurso.

Ahora bien, en un claro contraste empírico con los cerramientos celebracionistas de las narrativas más ahistorizantes, el concepto-estrategia de "cultura ciudadana" no se encontró con un camino despejado ni exonerado de fuertes críticas y dudas. Por ejemplo, tanta era la ambigüedad que despertaba la "cultura ciudadana" al comienzo que era casi increíble e insostenible que fuera el "programa bandera”, con mayor asignación presupuestal, del entonces elegido alcalde de la capital colombiana. A los pocos meses de su posesión en la alcaldía, el Concejo pide una definición de la "cultura ciudadana" para poder operativizar el programa:

Por esa razón recomiendan definir en qué consiste la cultura ciudadana para de esa forma establecer cómo se va a hacer la inversión. Así mismo formular correctamente las metas y estipular el tiempo para su alcance, de tal forma que se permita evaluar la cuantificación y medición del impacto social deseado (El Tiempo, mayo 23 de 1995).

La preocupación en ese momento giraba alrededor de la pregunta sobre cómo iba a adelantar el programa de "cultura ciudadana" y el monto destinado a su ejecución:

[...] su idea [era] invertir 23.000 millones de pesos en un programa de cultura ciudadana, un ambicioso proyecto que pretende reeducar a los capitalinos en todo lo referente a la vida en comunidad. Aunque todo el mundo coincide en la necesidad de hacer algo en este campo en una ciudad donde ya es frecuente que los conductores desciendan de sus carros para liarse a puños, la cifra comprometida asusta un poco (Semana, enero 9 de 1995).

Sumado a este panorama, el Concejo de Bogotá de la época se opuso a la propuesta de "cultura ciudadana" que, en varios artículos, utiliza la denominación de educación ciudadana. Frente a la negativa del Concejo, Mockus decidió aprobar su Plan por decreto, a pesar de las dudas que seguían en el debate:

Nadie sabe qué va a hacer Mockus con la millonaria cifra de la educación ciudadana. Pero el desprestigio de la clase política es tal, que entre no saber qué va a hacer el alcalde con la plata o no saber qué va a hacer el Concejo con la plata, la gente escoge la primera opción, sin dudarlo un segundo (Semana, 1995).

A la estrategia de la "cultura ciudadana" para superar las dificultades del tránsito en Bogotá con mimos y teatreros o en su implementación de las tarjetas, se le reconocían sus méritos pero también sus limitaciones:

La cultura ciudadana, que ha sido la base de la estrategia de Mockus en materia de tránsito, ha dado buenos resultados, pero los capitalinos siguen pensando que es demasiado local, pues solo se ha aplicado en unas cuantas cuadras de la avenida 19. Allí, mimos y teatreros hicieron durante un mes un ejercicio de participación que resultó interesante, pues tanto peatones como conductores comenzaron a tomar conciencia de la importancia de respetar las señales de tránsito. Sin embargo, se corre el peligro de que la gente olvide rápidamente lo aprendido y el trabajo se pierda, pues no son suficientes unas cuantas horas para que los ciudadanos cambien su comportamiento (El Espectador, 7 de abril de 1995).

En los primeros días de la alcaldía de Mockus aparecen columnistas como German Andrade con una nota titulada Bogotá necesita algo más que educación ciudadana (El Espectador, 7 de enero de 1995, p. 4A). En su nota, Andrade escribía: "Tampoco la educación es la panacea. Esta se debe ante todo acompañar de cambios estructurales". De 
ahí que concluya que: “[...] preocupa, pues, [...] que una sociedad en crisis finque todas sus esperanzas en la educación de la conciencia ciudadana" (7 de enero de 1995, p. 4A). Incluso para una fecha tan tardía en la primera alcaldía de Mockus, cuando este renuncia para presentarse como candidato a las elecciones presidenciales, se encuentran fuertes críticas a algunas de las acciones emblemáticas de la cultura ciudadana. Así, la revista Semana registra la crítica por parte de los bogotanos frente al fracaso obtenido hasta el momento con la cultura ciudadana, "el caos en que se sumerge a diario Bogotá, campañas pedagógicas como la de los pasos de cebra, las tarjetas blanca y roja y el respeto por los ciclistas se han convertido más en anécdotas efímeras que en soluciones reales" (Semana, mayo 12 de 1997).

En una suerte de balance de la figura de Mockus y su gestión, la Revista Semana publica un artículo a la mitad de su primera administración en unos términos que hoy son brumosos y extraños para las imágenes más idealizadas del pasado:

Mockus como alcalde no ha sido ni muy bueno ni muy malo. Como símbolo de la antipolítica y con una inusitada campaña en la que hubo de todo menos manifestaciones, discursos en plaza pública, vallas, pasacalles y cuñas publicitarias, se hizo elegir con medio millón de votos, duplicando sin mayor esfuerzo a su más inmediato contendor. Es evidente que con su imagen de académico excéntrico, una reconocida trayectoria de honestidad y una clara actitud de rechazo a todos los valores y costumbres de la política tradicional, tiene convencidos a los desesperados habitantes de una Bogotá cada vez más caótica de que quizás él, con su peculiar estilo, puede lograr el milagro que nadie ha logrado hasta ahora: salvar la ciudad. Sin embargo ese milagro hasta ahora parece más una ilusión que una realidad. Mockus es un gran intelectual pero un regular administrador. Conceptualiza pero no actúa. No siempre la aptitud de conceptualizar y generar grandes ideas que poseen los académicos como él se traduce en capacidad para llevarlas a cabo. Y ese sin duda es el caso de Mockus. A pesar de que todos le reconocen que ha desempeñado su cargo con honestidad y responsabilidad, la impresión que tienen quienes han seguido de cerca su labor al frente de la Alcaldía es que ha sido lenta, desorganizada y que está muy lejos de poder calificarse como una buena gestión. Honesto y diferente. Las deficiencias de Mockus en el campo administrativo las ha compensado con un gran éxito en el campo didáctico. Es indudable que detrás de su éxito está el sello personal que logra imponerle a cada cosa que hace. No importa si se trata de un programa de educación ciudadana o de una intrincada controversia con el Concejo Distrital (Semana, 22 de abril de 1996).

No se puede afirmar que la cultura ciudadana haya estado exenta de disputas y de críticas, incluso en sus supuestos años dorados asociados a la primera administración de Mockus se encontraban notas en la prensa que indicaban que: "A pesar de su enorme popularidad no han sido pocos los bogotanos que han criticado el plan bandera de su administración, el de cultura ciudadana" (Semana, 12 de mayo de 1997).

Pero no todo era oposición y crítica. Desde el comienzo, las propuestas de Mockus tuvieron sus defensores. Una entrevista al por aquel entonces arzobispo de Bogotá, monseñor Pedro Rubiano, mostraba su apoyo a la política de Mockus: "Aquí falta conciencia ciudadana, amor por Bogotá, y por consiguiente no hay disciplina que solo se consigue con la educación sobre lo que significa la responsabilidad de ser bogotano o de vivir en Bogotá" (El Espectador, 16 de abril de 1995, p. 1-F); de ahí que confluyera con Mockus en la urgencia de intervenir los comportamientos "inadecuados" de los ciudadanos: "Hay que cambiar los hábitos inadecuados y volver a encontrar, entre todos, unos comportamientos que hagan que Bogotá sea la primera ciudad del país en disciplina, valores ciudadanos y respeto de los unos por los otros" (16 de abril de 1995, p. 1-F).

Al comienzo de la segunda administración de Mockus, en la prensa se encontraban fácilmente artículos donde se valoraba la experiencia de la cultura ciudadana de la primera alcaldía. Se indicaba como uno de los logros "[...] algo que parecía imposible: apaciguar y hasta cierto punto civilizar a los conductores y peatones de la ciudad. Los mimos, ubicados en ciertos cruces estratégicos del centro, les enseñaron a los conductores a respetar las cebras y a los peatones" (Semana, septiembre 17, 2001). 
Tras las alcaldías de Lucho Garzón, Samuel Moreno y Gustavo Petro se evidencia con frecuencia en artículos de prensa la nostalgia por la discontinuidad en la implantación y uso de la "cultura ciudadana”, desde nostálgicas apelaciones a lo que supuestamente se logró hasta a los desafortunados retrocesos ${ }^{8}$. Lo que nos da entender que a pesar de las críticas negativas, dudas y burlas a la idea de Mockus, una noción idealizada y romantizada de la "cultura ciudadana” logró hegemonizarse. Así, no es extraño que ante ciertos malestares con los bogotanos en sus prácticas diarias se suele "ingenuamente" reproducir el argumento de su "falta de cultura ciudadana" como explicación. Por supuesto, es más cómodo, intelectual y políticamente, atribuirle a los "bárbaros" por su renuencia a plegarse a la ley y la buena moral, los problemas de una ciudad, que preguntarse por cómo transformar realmente los privilegios y las desigualdades estructurales que benefician a la "gente de bien" de los estratos sociales en los cuales se añora y celebra la "cultura ciudadana".

\section{Conclusiones}

La producción de la figura de Mockus como un académico, un brillante filósofo cuyas acciones y pronunciamientos rayaban en la locura e incomprensión, fue fundamental para el efecto de autoridad que apuntaló la "cultura ciudadana". Para el grueso de los estudiosos de la teoría social y cultural, sin embargo, sus elaboraciones sobre el concepto de cultura y sus relaciones con la ley y la moral en un registro abiertamente estructural-funcionalista y habermasiano son bien simplistas, cuando no simplemente erradas. No obstante, no es la consistencia o profundidad de su manejo de la teoría social lo que ha sido significativo de Mockus, sino que haya logrado que sus concepciones-estrategias de "cultura ciudadana" se hallan en retrospectiva naturalizado de tal manera en los imaginarios sociales y políticos a pesar de sus evidentes apelaciones a un "pánico cultural" que reproduce un autoritarismo moral abiertamente eurocéntrico y clasista.

Nos llama la atención que las apelaciones a la cultura hayan devenido centrales a los discursos y tecnologías de gobierno, articulando una serie de imaginarios sobre un "pánico cultural" para legitimar no solo unas maneras de comprender los problemas de la ciudad, sino también para proponer sus soluciones. Asimismo, se hace muy interesante para nuestro análisis el poder de naturalización de estos discursos y tecnologías, que a la luz de la teoría social contemporánea pierden la inocencia y obviedades con las que se pretenden cubrir, para evidenciar un autoritarismo moral fundado en los efectos de verdad de discursos expertos que se cubren de objetividad.

El logro de la "cultura ciudadana" radica más en el efecto de hegemonización que clausura la crítica de las tecnologías de gobierno propias de una modalidad de biopolítica que opera desde una noción de cultura como "buena costumbre", de la cual se deriva una posición iluminista y moralista de unas autoridades que "enseñan" a otros a comportarse adecuadamente. Es en este sentido que se puede concluir que la "cultura ciudadana" debe entenderse como una tecnología de corregir comportamientos "inadecuados", una especie de "ortopedia ciudadana" en nombre de un supuesto "bienestar común" a través de la "convivencia" y el "respeto" que obnubila cualquier discusión sobre las relaciones de dominación y de despojo que reproducen la desigualdad social y los múltiples privilegios de unos pocos.

8 Ver, por ejemplo, El doloroso retroceso de la cultura ciudadana en Bogotá (Suárez, 2015). 


\section{Referencias}

Alcaldía Mayor de Bogotá. (2003). Cultura ciudadana: construcción de ciudad. Bogotá: Alcaldía Mayor de Bogotá.

Andrade, G (1995). "Bogotá necesita algo más que educación ciudadana”. En: El Espectador, 7 de enero. pág. 4-A.

Bromberg, P. (2010). ¿Cultura ciudadana y los retos del gobierno urbano, o el gobierno urbano y los retos de cultura ciudadana?". En Cultura ciudadana y gobierno urbano enfoques y nuevos escenarios (pp. 33-56). Bogotá: Alcaldía Mayor.

Corpovisionarios. (2016). Encuesta de cultura ciudadana. Recuperado el 16 de octubre de 2016, de http://www.corpovisionarios.org/index.php/ es/encuesta-cultura-ciudadana

El Espectador. (9 de enero de 1995). "Siete caras de la perinola”. pág. 1-E.

El Espectador. (6 de marzo de 1995). "Mockus invita a los ciudadanos a ser 'sapos' (cont)”. pág. 2-E.

El Espectador. (7 de abril de 1995). "Tránsito: la 'papa caliente' de Mockus".

El Tiempo. (23 de mayo de 1995). "Concejo pide definición de cultura ciudadana". Recuperado el 10 de octubre de 2016, de http://www.eltiempo. com/archivo/documento/MAM-330524

Hall, S. (2010). Sin garantias: trayectorias y problemáticas en estudios culturales. Popayán: Envión Editores.

Mockus, A. (1994). Anfibios culturales y divorcio entre Ley, Moral y Cultura. Análisis Político, (21), 37-48.

Mockus, A. (2001). Cultura ciudadana programa contra la violencia en Santa Fe de Bogotá, Colombia, 1995-1997. Estudio Técnico. Washington, D.C: Banco Interamericano de Desarrollo.

Mockus, A. (2004). Formación en cultura ciudadana: la experiencia bogotana. In Foro Educativo Nacional Competencias ciudadanas (pp. 3352). Bogotá: Ministerio de Educación Nacional.
Pombo, R. (1994). "El (¿nuevo?) país". En: Semana. Recuperado el 10 de octubre de 2016, de http://www.semana.com/opinion/articulo/ el-nuevo-pais/24280-3.

Rubiano, P. (1995). "La ciudad a los ojos de la iglesia”. En: El Espectador. 16 de abril. pág. 1-F.

Semana. (17 de septiembre de 2001). "Bogotá está de moda”. Recuperado el 9 de octubre de 2016, de http://www.semana.com/especiales/articulo/ bogota-esta-moda/48726-3

Semana. (11 de junio de 2001). "¿El frenazo?". Recuperado el 9 de octubre de 2016, de http://www.semana.com/nacion/articulo/ el-frenazo/46291-3

Semana. (4 de diciembre de 2000). "Mockus modelo 2000". Recuperado el 10 de octubre de 2016, de www.semana.com/nacion/articulo/ mockus-modelo-2000/44247-3

Semana. (12 de mayo de 1997). "El clon de Mockus". Recuperado el 11 de octubre de 2016, de http://www.semana.com/gente/articulo/ el-clon-de-mockus/32390-3

Semana. (22 de abril de 1996). "Desde el balcón". Recuperado el 9 de octubre de 2016, de www.semana.com/nacion/articulo/desde-elbalcon/28441-3

Sommer, D. (2006). Cultural agency in the Americas. Durham: Duke University Press.

Suárez, R. (2015). El doloroso retroceso de la cultura ciudadana en Bogotá - Bogotá - El Tiempo. El Tiempo. Recuperado el 11 de octubre de 2016, de http://www.eltiempo.com/bogota/culturaciudadana-en-bogota-el-doloroso-retroceso-dela-cultura-ciudadana/ 15864104

Tognato, C (n.d.). Cultural Agents Reloaded. The Legacy of Antanas Mockus. Cambridge: Universidad de Harvard. 